\title{
New Design for Creating Safe Places to Reduce Earthquake Loss and the Best Way to Rescue and Relief People
}

\author{
Reza Dorri, Amir Mahmoud Zadeh*, Manuchehr Babadi \\ Department of Civil Engineering Earthquake Group, Shakhes Pajouh Search Institute, Isfahan, Iran \\ Email: ^Amiramj@yahoo.com
}

How to cite this paper: Dorri, R., Zadeh, A.M. and Babadi, M. (2018) New Design for Creating Safe Places to Reduce Earthquake Loss and the Best Way to Rescue and Relief People. Open Journal of Geology, 8, 913-924.

https://doi.org/10.4236/ojg.2018.89054

Received: May 17, 2018

Accepted: August 24, 2018

Published: August 27, 2018

Copyright (c) 2018 by authors and Scientific Research Publishing Inc. This work is licensed under the Creative Commons Attribution International License (CC BY 4.0).

http://creativecommons.org/licenses/by/4.0/ (c) (i) Open Access

\begin{abstract}
Immunization and upgrading of structures are for the prevention of physical and financial losses due to earthquake. The importance of structures is not the same regarding the physical and financial losses caused by the earthquake damage, although the responsibility to improve and secure them in terms of providing financing according to the type of ownership is different. The formulation of rules, regulations and necessary letters, the supervision over the various stages of immunization, and the establishment of appropriate facilities are in accordance with the financial and executive capacity of the country, the prioritization and preparation of a major plan for the improvement and securing of government responsibilities. Old buildings in worn-out textures generally have a wall system without vertical and horizontal shafts. The experiences from Boijin Zahra, Tabas, Rudbar and Bam earthquakes indicate that the destruction of such buildings in the time of devastating shakes is definite. The importance of structures is not the same considering the physical and financial losses caused by the earthquake damage. The principal destruction and rehabilitation for prevention of physical and financial losses due to the earthquake in terms of providing financing and according to the type of ownership varies, and this requires a rebuild time and high costs for the employer. Therefore, it is recommended that according to the conditions of the buildings of the country, arrangements and decisions, whether for financial facilities, etc. are considered so that everyone can carry out the executive steps of the safe room according to their existing structures.
\end{abstract}

\section{Keywords}

Improvement, Immunization, Safe Room, Earthquake, HAZUS Methodology 


\section{Introduction}

It's only a century since we became aware of the nature of earthquakes and their productive. We have found that earthquakes are not accidental, but rather natural forces that arise in the evolution of the planet. Today, earthquakes can be mapped, measured and analyzed; we know where they are likely to occur, and earthquake forecasting methods will soon reduce our uncertainty about the location and time of the next earthquake event. But in many parts of the world, especially in areas that are most at risk, old attitudes and beliefs persist; attitudes such as belief in determinism and lack of interest in the fact that they can and have power to fight this destructive force; therefore, they are reluctant to plan and spend on immunization against earthquake.

In the $21^{\text {st }}$ century, the explosive and asymmetric increase in world population growth, as well as the growth of the size and number of villages and cities on the planet, complicates the situation. In today's world, unlike past centuries, there is less space on the earth that the earthquake in that place does not cause any damage. As urbanization widespread, the potential for further destruction increases. For this reason, now more than ever in history, the probability of a catastrophic event due to earthquake has risen and is increasing. Destruction of cities and regions around the world has been widespread in natural disasters in recent decades, as unprecedented in comparison with the previous century. Despite the world's major efforts to improve earthquake safety, we should expect similar and larger accidents in the coming years.

However, in recent years, our science and experience has increased dramatically with regard to how to protect ourselves, buildings and cities against earthquakes. The core of the research teams is to overcome this potential danger, consisting of engineers, urban planners, finance professionals, managers and government employees. In the process of immunization against earthquake hazards, the use of various specialties is required because a wide range of information and measures should be taken into account, such as special attention to immunization methods, designing more robust buildings and improvement of the quality of construction in parts in which the probability of an earthquake is higher.

Immunization against earthquakes covers all individuals. The public must be aware of the security of the type of building they are living and the resistance of their building and their workplaces to the earthquake. The construction industry is responsible for improving buildings design and quality improvement. Politicians and managers manage risk by deciding on the cost of earthquake immunization and how to use financial resources. Many people are directly or indirectly involved in this process, such as urban designers to design safer cities, community associations by fostering ready-made forces for relief in future earthquakes and encouraging their members to immunization, private companies and organizations protecting themselves, their employees and their clients, and insurance companies to protect themselves by risk assessment and provision of coverage for individuals [1] [2]. 
After the terrorist attacks on the Twin Towers of the World Centers in 2001 in New York, the attitudes and desires of structural engineers, especially the towers, have been increased into passive defense tales and the stabilization of high structures against unpredictable and protracted loads, such as explosions and fires. In the same time after the devastating earthquake of January 2003 in Bam and the provision of municipal services commissioned by the Mayor of Tehran for the city of Bam, a committee was set up for retrofitting, and the work started in February 2003 by the committee on the idea of a safe room, which, following research and experimental activities, was finalized in late March.

Activities carried out in order to achieve life safety during an earthquake and the rescue and relief to the people are taken place after the earthquake. In the best of the matter, doing and fulfilling of recommended issue a private sector can cover the life safety during earthquakes. So far, articles have been gathered in this regard.

The distinction of this with the work of others is that this design is feasible for any building with any condition that does not have the ability to sustain the structure against the earthquake and the lateral loads, and is feasible with the least possible cost and the least space and the shortest possible time. Regarding innovation, it can be stated that it is no longer expected to overwhelm the construction of the previous building, and to rebuild the structure of new building from the beginning to the end to provide earthquake and sustainability forces.

\section{Literature Review}

\section{Security after earthquake}

Damaged buildings that continue to pose a danger to pedestrians should be secured. This should be done under the supervision of experienced engineers and accident managers should use engineers to restore security to the community. It is a priority to start immunization with buildings that are located next to the main streets and half of their walls are collapsed, their construction components are in high-risk conditions or have signs of instability, such as a bulge in buildings. All cracked walls are not unstable, but need more detailed studies to determine their durability, which we do not have enough time in the emergency phase. If they are suspicious in sustainability, the best way is installation of a buffer for the suspected members to prevent its movement in the future (Figure 1). Scaffoldings can also be used, which are very suitable for side buffers for wide views. Designing the buffers requires skills and should be supervised by professional engineering. The buffers are designed to create forces resistant to subsequent movements resulting from the destruction of components. If the two arms of the wooden beams or the retaining (buffer) members are properly tightened, then they will create a backrest. Keeping damaged parts, especially in building structures, should be done by a reinforcing plate (a beam or wooden beams that are glued to the wall to distribute point load at a level of the building) [2] [3] [4].

If possible, hazardous components such as floating building slabs, disconnected 


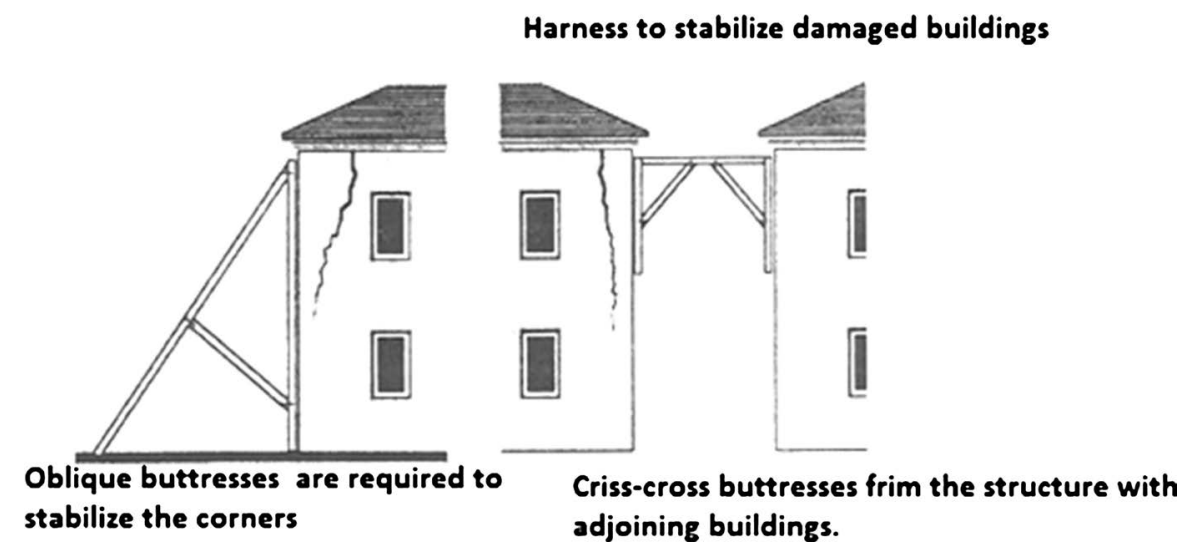

Figure 1. Immunization damaged buildings in crowded places [2].

roof beams or damaged architectural decoration should be removed. The smaller parts can be separated by hand from its loosed backing. Large floating parts or ceiling slabs, or FALLING walls, should be destroyed if threatened. This requires heavy machinery, especially to drag or drop hazardous components by keeping distance from the building [3].

\section{Methodology}

\section{HAZUS loss estimation methodology}

HAZUS methodology is a predicting method for estimating losses based on new practices based on the design of new buildings and the improvement of existing buildings. By using these methods for each building the definition of earthquake movement levels is possible with regard to the range of post-earthquake damage levels from no damage to complete destruction. Such methods can be used both for evaluation and for design: that is, they can be used to assess the probable situation of an existing building after a specific earthquake, as well as for the design of new buildings (or retrofitting of existing buildings). The HAZUS methodology in the United States has been developed by the community or local authorities as part of nationally supported FEMA program to enable the assessment and mitigation of the earthquake risk (and other hazards) [4] [5] [6] [7].

\section{Loss levels}

The HAZUS method for assessing the damage (losses) caused by earthquake is the definition of the level of damage (loss) to the building based on the relative change of position between the classes (floors) at the level of maximum displacement of the building. Damage (loss) levels (with mild, moderate, severe and complete titles) are defined are defined for each building category with partial indexes to determine the level of damage (loss) per situation. Figure 2 shows a sample of appropriate damage levels for reinforced concrete skeleton structures with moderate heights. For each of the construction categories, each of these levels of damage (loss) is related to a certain degree of relative lateral displacement between floors, which leads to this level of destruction [4]. 


\begin{tabular}{|l|l|}
\hline \multicolumn{1}{|c|}{ Description } & Loss level \\
\hline $\begin{array}{l}\text { Thin diagonal cracks } \\
\text { (sometimes horizontal on } \\
\text { most of the inner walls; } \\
\text { Cracks at the intersection of } \\
\text { the frame with the filler wall }\end{array}$ & $\begin{array}{l}\text { Mild } \\
\text { structural } \\
\text { loss }\end{array}$ \\
\hline $\begin{array}{l}\text { The surface of the often-filled walls } \\
\text { has large, diagonal or horizontal } \\
\text { cracks; bricks of some walls are } \\
\text { crushed at the intersection of the } \\
\text { beam-column. The diagonal shear } \\
\text { cracks are seen in beams or concrete } \\
\text { columns }\end{array}$ & $\begin{array}{l}\text { Moderate } \\
\text { structural }\end{array}$ \\
\hline $\begin{array}{l}\text { Most filling walls have large cracks; } \\
\text { some of the bricks collapse; some } \\
\text { filler walls are removed from the } \\
\text { plate; several walls are partially or } \\
\text { completely overturned; several piles } \\
\text { of concrete or concrete in the section } \\
\text { are accompanied by partial loss. The } \\
\text { structure has permanent } \\
\text { deformation }\end{array}$ & $\begin{array}{l}\text { Structural } \\
\text { loss }\end{array}$ \\
\hline $\begin{array}{l}\text { The collapsed structure is subject to } \\
\text { severe destruction due to partial } \\
\text { or complete destruction of the } \\
\text { filling walls and the concrete beams } \\
\text { and columns are exposed to } \\
\text { destruction }\end{array}$ & $\begin{array}{l}\text { Complete } \\
\text { structural } \\
\text { loss }\end{array}$ \\
\hline
\end{tabular}

Figure 2. Loss levels for reinforced concrete buildings with low and intermediate height: HAZUS loss estimating methodology [4].

Functional point for a building and for each specific movement of earthquakes, the displacement between floors is calculated based on the spectra displacement of the entire building against the motion. This spectra displacement at a point called the "point of action" obtained from the intersection of the "demand" of the earth's movement from the building and the "capacity" of the building as a response-capacity curve, which reflects the reactionary response of a system having a degree of freedom, considering the reduction in the quality of the building during the shakes, will be calculated. Both demand and capacity are defined by the spectral acceleration curves (sa) against spectral displacement (sd), and the action point ( $\mathrm{Sa}, \mathrm{Sd}$ ) is the intersection of these two curves.

\section{Capacity curve}

Precise rules for building standard capacity curves for each building group are provided in the HAZUS Guide. Capacity curves are based on static pushover curves and obtained using the concepts described in ATC-40 and FEMA273.

\section{Demand curve}

The demand curve is based on the response curve of the damping spectral reactive response, which is based on the spectral scales of the Earth's motion and is adapted to the soil conditions of the site. This is done taking advantage of the spectral reduction factors for the increasing precipitated damping, when the 
building passes from reactionary to non-reactionary response. The rules of making these factors are associated with a distinctly reduced spectrum; this depends on the shape of the capacity curve up to that amount of displacement as well as the quality reduction factor, in order to considering the damping rate reduction in the weak buildings, which depends on the duration of shakes and the condition of the building.

\section{Distribution of loss}

Estimating the performance of a group of buildings belonging to a special construction group would be possible when a specific earthquake occurs, using the spectral response of the building at the performance point of a standard building in that group, as described above, along with four fragility curves for that group, which indicates the possibility of placing a building in one of the four levels of loss after the occurrence of shakes at each spectral response level. The general form of each of these curves is assumed to be a normal log and is defined by two indices: a mean value and a coefficient of variation. These curves are used to determine the distribution of a group of buildings between the four levels of loss. In the HAZUS guide, the parameters necessary to construct these fragility (brittle) curves are expressed for all the 36 main building groups identified in the American classification of buildings and for zones with different seismic design requirements.

The spectral response used for most types of construction, as described above, is a spectral displacement (these types of construction are known as "sensitive to displacement" or "sensitive to lateral displacement", however, some of the facilities and components of construction and equipment are one of the most important applications for estimating losses, thus, their application is the assessment of the impact of an improvement program to improve the condition of traditional homes and compare the efficiency of different levels of refining technology, of course, if relative vulnerabilities are known or can be calculated. The effect of different levels of retrofitting, as shown in the figure, is shown in the figure for the number of dead and houses destroyed in eastern Turkey for a period of 25 years. Such data can be used to evaluate the cost-benefit or cost-the effectiveness of government interventional plans [4].

\section{Estimating loss in urban areas}

To estimate loss in urban areas, it can be assumed that after a earthquake occurring within a short distance from the city, the decrease in earthquakes throughout the city is negligible. Therefore, the standard risk assessment methods can be used with the most appropriate earthmoving indicator. The vulnerability assessment for these areas is much more complex than rural areas, because most urban habitats cover a wide range of building types with various vulnerabilities to earthquakes, where the site conditions are also different.

A method for assessing loss, is the division of urban areas into several vulnerability zones, and the types of construction within each of these zones are assumed to be the same, also the condition of the soil is assumed uniformly and the total population (or the number of settlements) are identified. The zoning of 
urban areas is carried out using large scale maps or aerial mapping of the city using the underlying soil maps and local surveys. Areas that are constantly under the supervision of management, such as urban areas or sectors, are more appropriate because they are registered in these building data or population data units.

\section{Secure room layout}

The design of the secure room is related to old buildings in worn-out textures. These buildings generally have a bubble wall system without vertical and horizontal rewinding which destruction during the devastating earthquake earthquakes is decisive. According to Figure 3, in this plan, a metal molding inside each floor of this type of building is foreseen to prevent debris from falling into the earth after the earthquake and demolition of the building [5] [8] [9].

\section{Results}

\section{Operational inspection of the safe room}

\section{How to install a safe room structure}

In the prefabricated system chosen for this project, the can profiles have been used. These profiles can slide inside each other. Therefore, the dimensions of the metal frame of the safe room in the longitudinal, transverse and altitudinal directions can be changed and easily arranged in rooms with different dimensions. It should be noted that many studies have been done on the behavior of can sections in dynamic loading, and their performance in this situation is largely determined. Figure 4 shows the placement of the column in the corner of the room.

\section{Inserting the beams}

At this stage, first beams are inserted between the columns (Figure 5(a)) and then the middle beams are placed in their place (Figure 5(b)). It is necessary to explain that all these components can also be slid in each other and allow the structure to change the dimensions of the plan.

After complete installation of the structure at a height of 1.5 meters, as shown in Figure 6(a), the metal nail is connected to the beam beams by welds at intervals

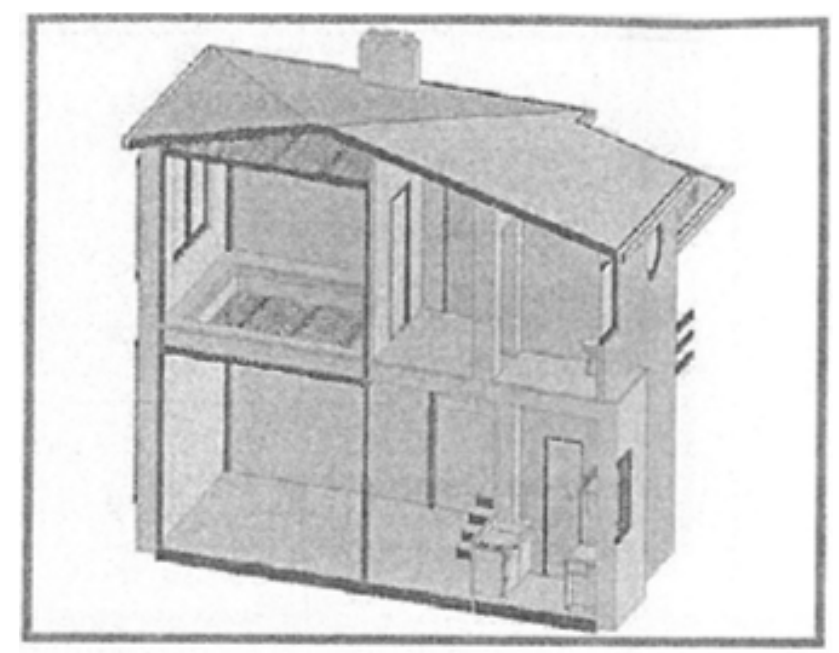

Figure 3. Placing the safe room structure inside the building [5]. 


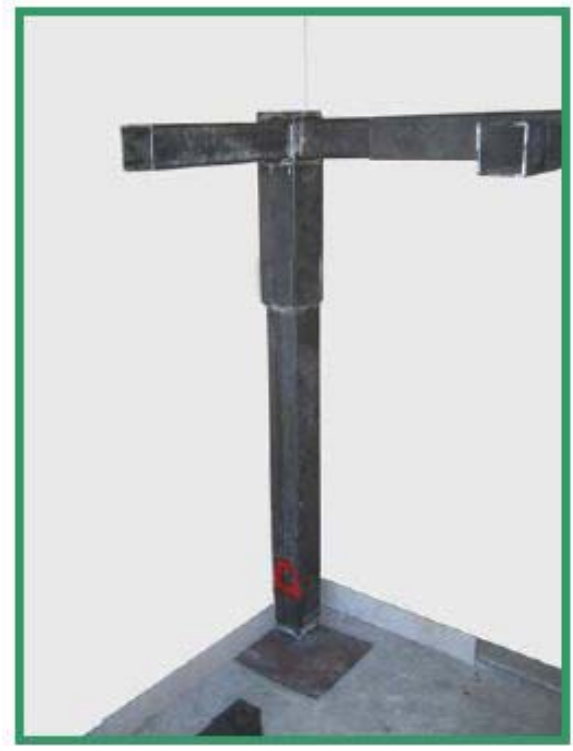

Figure 4. How to place the column in the corner of the room.

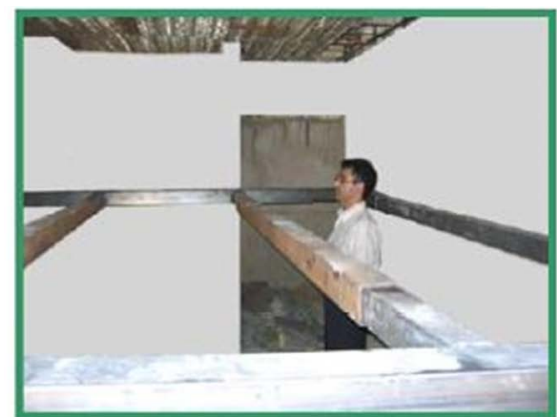

(a)

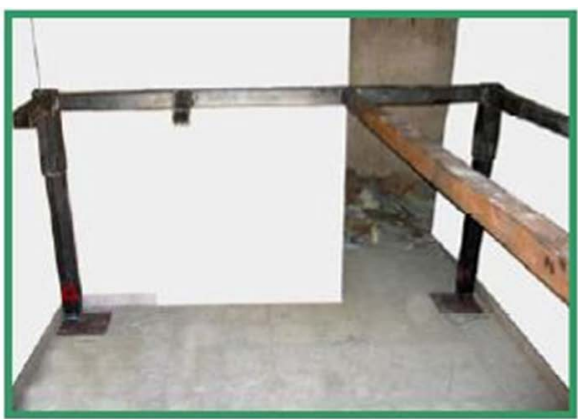

(b)

Figure 5. (a) Inserting the beams between the columns; (b) Inserting the middle beams in their place.

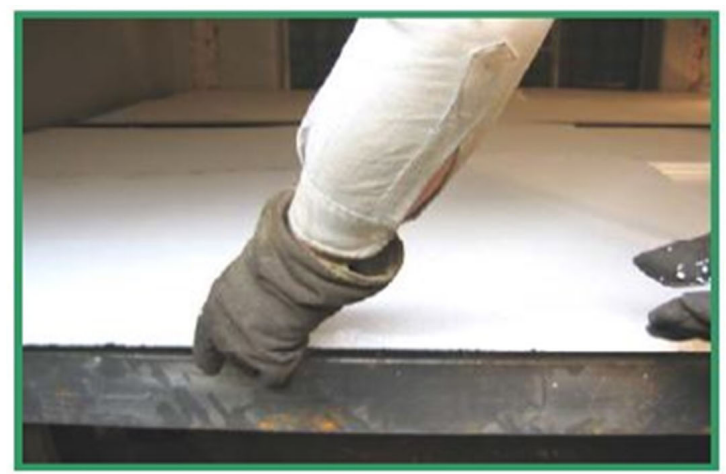

(a)

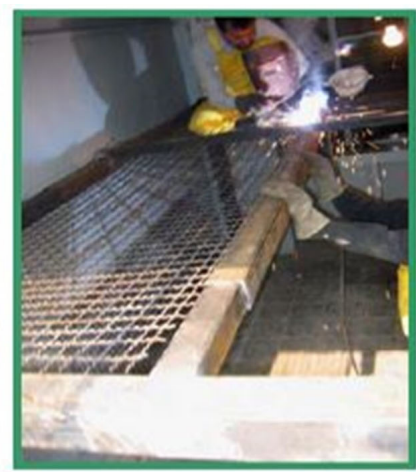

(b)

Figure 6. (a) The connection of metal net of the roof to the beams and (b) fitting the foam to the roof bumper at a height of 1.5 meters.

of $20 \mathrm{~cm}$, and the foam is placed on it (Figure 6(b)). The performance of the light ceiling is due to the fact that people save lives against falling debris.

Lifting the structure by the jack to the bottom of the room: After the structure 
was installed at a height of 1.5 meters, the person who installed the metal net (grid) and foam bumpers from the upper part of the room door, the height of which is often about $2 \mathrm{M}$, is exited. Then, in accordance with Figure 7, the structure is lifted by a jack and adhered to the roof of the room. After this step, the middle part of the column is welded in accordance with Figure 8(a), and then the lifting jacks are released as shown in Figure 8(b).

\section{Connecting the columns to the floor}

The plate of the columns after the lifting of the structure and finishing the welding operations at all connecting points, are molded to the mosaic according to Figure 9. Then the upper parts of the screws are welded to the plate of the columns (Figure 10(a)) and the parts of the screws that are placed above the column plate are cut in accordance with Figure 10(b) to its upper part is aligned with the plate of the column (Figure 11).

Safe room run should be carried out under the supervision of an experienced engineer with a history working especially in metal joints and all tests for welding, bending and stretching and so on.

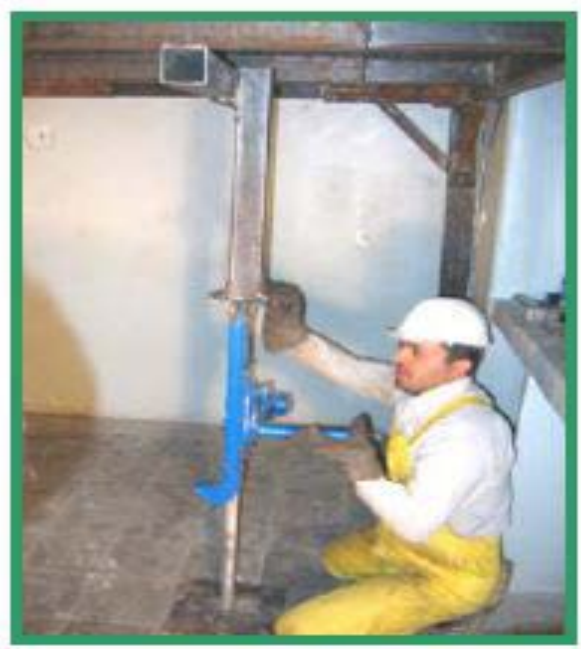

Figure 7. Lifting the roof of the structure by means of a jack.

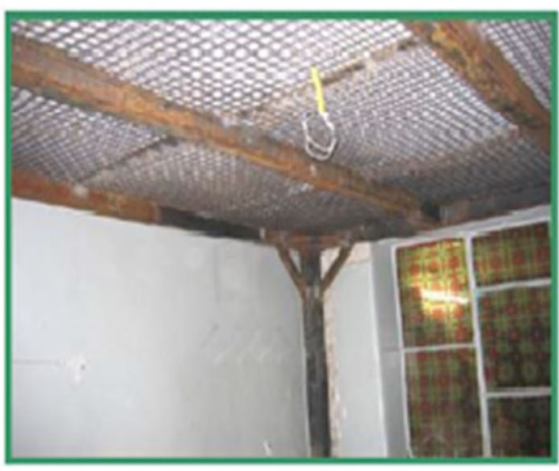

(a)

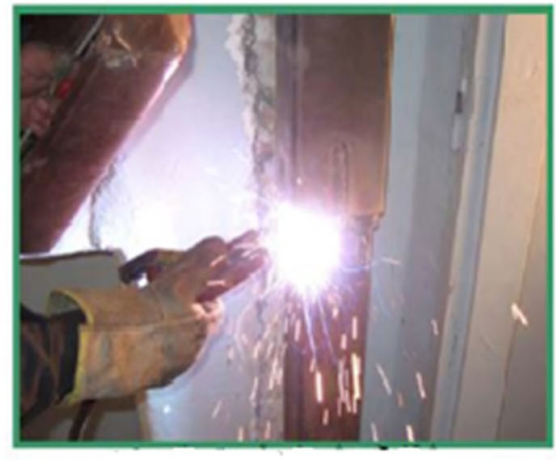

(b)

Figure 8. (a) Welding the middle of the column; (b) The final design of the structure after the jacks are released. 


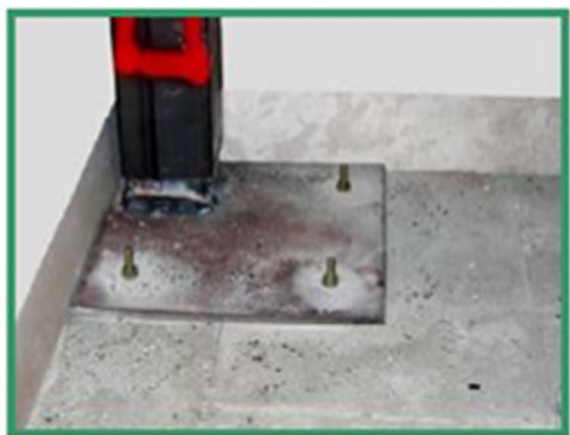

(a)

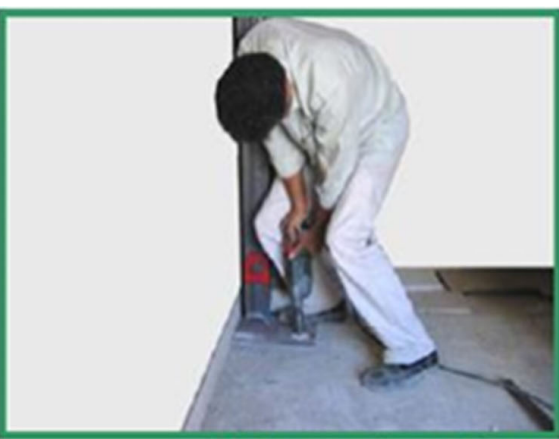

(b)

Figure 9. Piercing the floor mosaic and screwing the plate to the column.

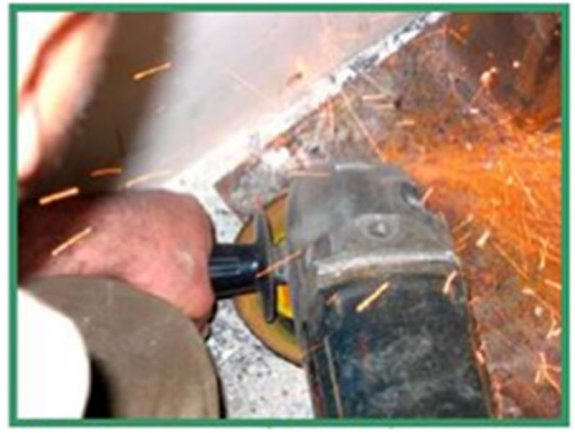

(a)

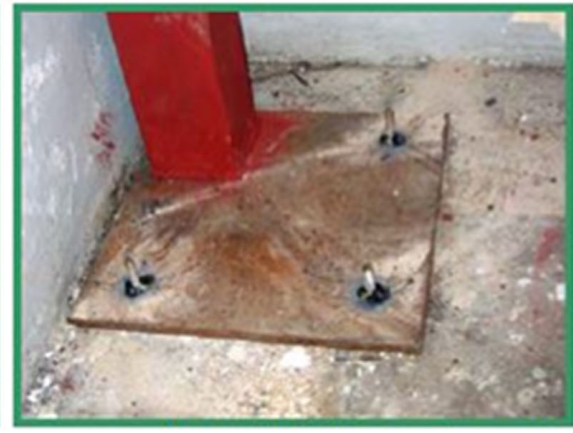

(b)

Figure 10. (a) Welding the screws to the column plate and (b) Scouring the upper surface of the screws.

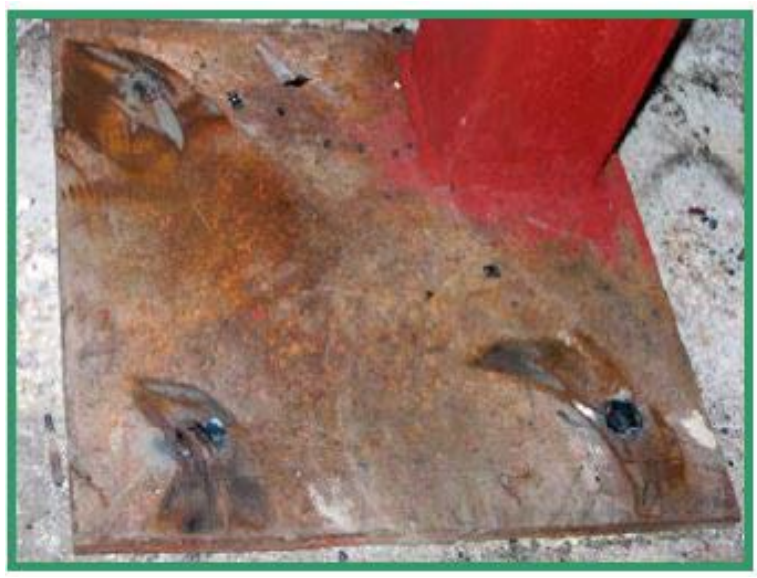

Figure 11. The upper surface of the column after finishing the work.

\section{Conclusions}

The growing trend of the scientific advances of various societies and its positive effects on the safety of human life has always proved contrary to the fact that human beings are accused of destroying against the injuries and disasters caused by the environment. The equipping of cities with urban planning methods and models to reduce the risk of earthquakes is the most important urban rescue approach. Recognizing the vulnerability of the population and human groups has 
been considered as a means of preventing the emergence of a life-threatening disaster in high risk areas. Undoubtedly, reducing the casualties and increasing the social security factor and, more importantly, maintaining human and inhumane human resources of the residential complex are among the main duties of any government.

The analysis of the vulnerability of population centers in risk areas is a scientific action to provide appropriate intelligence infrastructure on the degree and risk level of a risk incident. Based on this viewpoint, the problem of vulnerability analysis resulting from the proposed map can be considered as an important tool for dealing with crises caused by earthquakes in the future.

First, the assessment of the risk and the crisis requires a comprehensive approach in which different approaches, such as urban planning, are used. Establishing this communication serves as a tool to reduce the vulnerability of cities and to develop harm reduction policies and programs. In such a case, based on a rationalist approach and through the use of different criteria in macro and micro scale, it is possible to combine the complex, multi-dimensional variables, quantitative and qualitative criteria, and the rational result to be made. This estimation process works through the use of vulnerability assessment relationships and the determination of the coefficients of the importance of each criterion over other criteria.

\section{Conflicts of Interest}

The authors declare no conflicts of interest regarding the publication of this paper.

\section{References}

[1] Bommer, J., Spence, R., Tabuchi, S., Aydinoglu, N., Booth, E., del Re, D., Erdik, M, and Peterken, O. (2002) Development of an Earthquake Loss Model for Turkish Catastrophe Insurance. Journal of Seismology, 6, 431-446.

https://doi.org/10.1023/A:1020095711419

[2] UNDRO (1979) Natural Disasters and Vulnerability Analysis. Report of Expert Group Meeting. Office of United Nations Disaster Relief Co-Ordinator (UNDRO), Palais des Nations, CH-1211 Geneva 10, Switzerland.

[3] Stephens, L.H. and Green, S.J. (1979) Disaster Assistance: Appraisal, Reform and New Approaches. New York University Press, New York. https://doi.org/10.1007/978-1-349-05169-4

[4] FEMA (1999) HAZUS Earthquakes Loss Estimation Methodology. US Federal Emergency Management Agency, Washington DC.

[5] Spence, R. (2000) Recent Earthquake Damage in Europe and Its Implications for Loss Estimation Methodologies. In: Implications of Recent Earthquakes for Seismic Risk, Imperial College Press, London, Chapter 7, 77-90. https://doi.org/10.1142/9781848160194_0006

[6] Lei, Y. (2007) The Planning and Construction of Urban Disaster-Prevention Parks in Japan after the Hanshin Awaji Earthquake. Chinese Lanscape, No. 7, 13-15.

[7] Chi, Z. and Dai, H. (2011) Research on Great Kanto Earthquake in 1923 and Res- 
cue-Take Shen Bao as Center. Journal of Anhui Normal University (Humanities \& Social Sciences), 39, 476-481.

[8] Lv, Y. and Yan, D. (2004) Preliminary Study of Urban Disaster-Prevention Space System Planning. Journal of Zhengzhou University (Engineering Science), 25, 33-36.

[9] Wang, J., Ed. (2011) Main Progress and Enlightenment of Foreign Disaster Economics. Journal of Northwest A\&F University (Social Science Edition), 11, 111-120. 